\title{
Transforming assessment - Critical reflections around resolving tensions between assessment for learning and of learning
}

\author{
Sabina Cerimagic and Priya Khanna
}

The University of Sydney

\begin{abstract}
Current assessment and progression policies and practices in higher education are largely dominated by dichotomy between formative and summative assessments. Given assessments are major drivers of learning, such as dichotomous assessment systems which promote the learning that can only be tested via summative assessments and falls short in fostering complex graduate attributes - such as interdisciplinary competencies. Medical programs, across the globe are now embracing emerging concepts such as programmatic assessment that allows the assessments to serve 'for, of and as' learning. Given the most challenging curricular reform in any field, including Business is reforming assessments, this paper critically reflects on how emerging concepts such as programmatic assessment are promising in resolving the tensions created by dichotomy of assessment for vs as learning. The reflections are based on rapid scoping review of programmatic assessment in Medical education, as well as authors' familiarity with implementation of programmatic assessment in the Sydney Medical School renewed curriculum. There are many lessons that can be learned and carried over from the University of Sydney Medical curriculum to the Business education space.
\end{abstract}

Keywords: authentic assessment, assessment reform, programmatic assessment, learning, curriculum design and redesign

\section{Background}

Current assessment practices in Higher education institutions are dominated by a system of assessment of learning which privileges objective, structured quantification of student performances. Thus, higher learning institutions find it challenging to implement assessment reform. Given the emphasis on achievement of complex graduate attributes such as influence, leadership and working in multidisciplinary teams, novel systems of assessment should promote authenticity, agility, adaptability, and meaningfulness - rather than focusing on those attributes that can be tested via objective and standardised tools.

In recent years, the field of Medical education has made significant paradigm shifts in proposing newer approaches to assessment such as programmatic assessment (PA). PA is a concept that fosters assessment 'for', 'of', and 'as' learning by using carefully selected and collated data on students' longitudinal progression in various competencies from multiple sources including narrative-rich feedback.

In this paper, based on a rapid review of programmatic assessment, the authors critically reflect on how Medical education is attempting to resolve the tensions created by dichotomous assessment system and what lessons can be learnt to improve assessment practices in Business education.

\section{Methods}

Using Sydney Medical School as an example and based on authors' experiences of working in the field of Medical education as well as, in light of rapid scoping reviews on programmatic assessment the authors critically reflect on what lessons can be learnt for Business schools.

The practice and principles to programmatic assessment practice was informed by internal and external consultations; as well as the literature (Van Der Vleuten et al., 2015, Wilkinson \& Tweed, 2018, Norcini et al., 2018).

These include:

- multiple, continuous, and information-rich assessment data collected longitudinally

- assessments to be integrated across vertical themes, based on learning objectives, outcomes, and yearly capabilities 
- assessments are collated and accessed by means of an electronic portfolio (ePortfolio)

- assessment outcomes are focus on feedback using quantitative as well as narrative data

- a learning advisor model is used to provide individualised feedback, and to identify students requiring remediation and further assistance

- progression decisions are made on a holistic appraisal of the ePortfolio, which incorporates

- assessments for all vertical themes as well as attendance and professional conduct and communication.

\section{Finding}

One of the major changes in the new Medical curriculum, which some Business curriculums are facing too, was the introduction of a programmatic approach to assessment. Aligned with the learning outcomes, and relevant teaching-learning tasks, programmatic assessment involves continuous, authentic, and timely assessments throughout the year to enable a holistic view of student progression in all the capability areas. Guided by a Learning Advisor and enabled by an electronic portfolio, programmatic assessment aims to foster self-regulated learning in which students are responsible to ensure that their portfolio has met all the required standards satisfactorily to progress to the next level. The Sydney Medical School, for instance, uses an overarching educational design that aligns learning outcomes and assessment to a wide range of learning and teaching methods, that are evidence-based, and learner-centred (Pathak, Roberts, Lane, Bleasel and Cerimagic, 2019).The choice of particular method and task is dependent upon the expected learning outcomes, learning environment, the nature of the competencies that students need to acquire, alignment with assessment tools, the stage reached in the Sydney Medical Program and pragmatic considerations - such as teaching staff availability, spaces and resources. All of this is relevant when redesigning a Business curriculum that aims to introduce authentic assessments.

The methods have been based on a growing body of literature that has consistently highlighted the need to rethink traditional didactic pedagogical approaches towards more learner-centric learning and teaching methods that foster development of the competencies expected of the graduate. The first two years of the Sydney Medical program integrate authentic case-based small group teaching with online learning, using flipped classroom approaches. Existing piloting of this approach in the current curriculum demonstrates enhanced learning outcomes by fostering intrinsic motivation, engagement, higher-order thinking and problem-solving skills among students. Many teaching and learning innovations to be introduced in the new program have been successfully piloted in the current program, such as Team Based Learning (TBL) and flipped classroom. The Sydney Medical program's assessment philosophy is to introduce and continue to develop a system of programmatic assessment which retains the five key purposes of this approach, as outlined in the 2018 Consensus framework for good assessment for health professions (Norcini et al., 2018).

1. Optimising the impact of assessments on learners

2. Providing student feedback on strengths and weaknesses

3. Improving student self-regulated learning

4. Motivating students to focus on improvements

5. Improving instructional effectiveness

This approach to the implementation of programmatic assessment has delineated assessment components that can assess themes, capabilities and graduate qualities in an integrated way that mirrors the teaching of these components in the curriculum with clearly expected standards (Cerimagic and Khanna 2019).

By using purposefully selected multiple assessment tasks, designed to sample across the expected competencies and combined over the full academic year, the assessment strategy allows for the creation of a rich and longitudinal flow of triangulated information about each student's progress in various capability areas. Evidence for the validity of this approach has been outlined in previous studies using Kane's framework (Schuwirth and van der Vleuten, 2012).

\section{Conclusion}

Using Sydney Medical Program as a case study, it has been highlighted how assessment for learning instead of assessments for learning could be successfully achieved in a Business education context. As underpinned by the theory of programmatic assessment, the dichotomy of formative and summative assessments can be effectively replaced. In its place, a system of compulsory assessments which will be on a continuum of stakes (i.e., low, 
medium, high) can be adopted for authentic Business assessments. The stakes of the assessments of course must be considered, in making holistic progression decisions on the ePortfolio and formulating remediation. A balance between and within assessments can be ensured, not in terms of their typology of formative versus summative, but in terms of their utility in relation to feedback, remediation, and progression decisions.

This critical viewpoint offers an innovative perspective on the fundamental problem of the relationship of assessment and learning to advance understandings of applying assessment of and for learning within the same program. The authors in the presentation will make recommendations for practical tools addressing use of language, assessment task design, validity coherence, and student engagement and agency to promote assessment of learning.

\section{References}

Cerimagic, S. (2020) Medical health education curriculum reform and it's trials and tribulations. Short Communication. The Association for Medical Education in Europe (AMEE) Conference, Virtual Conference.

Cerimagic, S., (2020) How to persuade stakeholders to 'buy into' new Medical educational initiatives? Australian \& New Zealand Association for Health Professional Educators (ANZAHPE) Conference, Melbourne, Australia.

Cerimagic, S., and Khanna, P., (2019) An Integrated Medical Program. Australian \& New Zealand Association for Health Professional Educators (ANZAHPE) Conference, Canberra Australia.

Cerimagic, S., and Khanna, P., (2019) Change management: promoting communication and stakeholder involvement. Short Communication. The Association for Medical Education in Europe (AMEE) Conference, Viana, Austria.

Cohen S. J. and Van Ver Vleuten C.P.M. (2010). A standard setting method with the best performing students as point of reference: practical and affordable. Medical Teacher, 32, 154-60.

Homer M, Fuller, R. \& Pell G. (2018). The benefits of sequential testing: Improved diagnostic accuracy and better outcomes for failing students. Medical Teacher, 40, 275-284.

Khanna, P., Cerimagic, S., Roberts, C. (2019) Curriculum Renewal Through Design Thinking. Australian \& New Zealand Association for Health Professional Educators (ANZAHPE) Conference, Canberra Australia.

Pathak, P., Roberts, C., Lane., S., Bleasel, J., and Cerimagic, S. (2019) Curriculum Redesign of a Graduate Entry Medical Program using Systems Thinking Approach. Short Communication. The Association for Medical Education in Europe (AMEE) Conference, Viana, Austria.

Schuwirth L.W.T. and van der Vleuten C.P.M. (2011). Programmatic assessment: From assessment of learning to assessment for learning, Medical Teacher, 33(6), 478-485.

Schuwirth L.W.T. and van der Vleuten C.P.M. (2012). Programmatic assessment and Kane's validity perspective. Medical Education, 46, 38-48.

Van Der Vleuten C.P, Schuwirth L.W. (2005). Assessing professional competence: from methods to programmers. Medical Education 39, 309-317.

Van Der Vleuten C.P.M, Schuwirth L.W.T, Driessen E.W, Govaerts M.J.B \& Heeneman S. (2015). Twelve Tips for programmatic assessment, Medical Teacher, 37(7) 641-646.

Van der Vleuten et al. (2012). A model for programmatic assessment fit for purpose. Medical Teacher, 34, 205-214

Wilkinson, T.J. and Tweed, M. J. (2018). Deconstructing programmatic assessment. Advances in Medical Education and Practice, 9, 191.

Cerimagic, S. \& Khanna, P. (2020). Transforming Assessment - Critical reflections around resolving tensions between assessment for learning and of learning. In S. Gregory, S. Warburton, \& M. Parkes (Eds.), ASCILITE's First Virtual Conference. Proceedings ASCILITE 2020 in Armidale (pp. 318-321). https://doi.org/10.14742/ascilite2020.0143

Note: All published papers are refereed, having undergone a double-blind peer-review process. 
The author(s) assign a Creative Commons by attribution licence enabling others to distribute, remix, tweak, and build upon their work, even commercially, as long as credit is given to the author(s) for the original creation.

(C) Cerimagic, S. \& Khanna, P. 2020 